\title{
HLA-A gene knockout using CRISPR/Cas9 system toward overcoming transplantation concerns
}

\author{
Farshid Amiri ${ }^{1}$, Maryam Ranjbar ${ }^{1}$, Mohammad Pirouzfar $^{2}$, Marjan Nourigorji ${ }^{1}$ and Mehdi Dianatpour ${ }^{1,3^{*}}$
}

\begin{abstract}
Background: The treatment of many cancers and genetic diseases relies on novel engraftment approaches such as cell therapy and hematopoietic stem cell transplantation (HSCT). However, these methods are hindered by the alloreactive immune responses triggered by incompatible human leukocyte antigen (HLA) molecules. A successful HSCT procedure requires the eradication of donor and recipient HLA alloimmunization. Eliminating HLA-A gene expression using clustered regularly interspaced short palindromic repeats/CRISPR-associated protein 9 nuclease (CRISPR/Cas9) could be a great approach to increase the possibility of a successful HSCT through extending pool of unrelated donors.

Results: Our dual gRNA approach introduced a large deletion in the HLA-A gene. Among 22 single-cloned cells, two clones (9.09\%) and 11 clones (50\%) received homozygous and heterozygous large deletions, respectively. Finally, the real-time PCR results also revealed that HLA-A gene expression was diminished significantly.

Conclusion: The results suggested that CRISPR/Cas9 could be used as an efficient technique to introduce HLA-A gene knockout; thus, it can considerably lessen the burden of finding a fully matched donor by lowering the alleles required for a successful HSCT.
\end{abstract}

Keywords: HLA-A, HSCT, CRISPR/Cas9

\section{Background}

HSCT is a widely accepted approach for the treatment of many hematological malignancies and non-neoplastic disorders. However, serious challenges including stringent matching, donor insufficiency, engraftment rejection, and graft-versus-host disease (GVHD) may hinder the widespread clinical applications of this approach [1]. In this context, the major underlying issue is the incompatibility of HLA molecule expressed on the surface of various cells. Being located on chromosome $6 \mathrm{p} 21$, the HLA gene family is among the most polymorphic

\footnotetext{
*Correspondence: mdianatpur@gmail.com

'Department of Medical Genetics, School of Medicine, Shiraz University of

Medical Sciences, Shiraz, Iran

${ }^{3}$ Stem Cell Technology Research Center, Shiraz University of Medical

Sciences, Shiraz, Iran

Full list of author information is available at the end of the article
}

regions in human genome with a significantly low rate of linkage disequilibrium; thus, HLA compatibility between two individuals is considered a bottleneck in the field of HSCT.

HLA disparity between donor and recipient of HSCT leads to provoking the immune system [2] which consequently urges the patients to take immunosuppressive drugs. However, due to their immense adverse effects, the persistent usage of immunosuppressive drugs is limited. According to the National Marrow Donor Program guideline [3], in a safe allogeneic HSCT, donor and recipient alleles need to be matched at HLA-A/-B/-C/DRB1. Previous studies have revealed promising solutions to the above challenges by eliminating HLA complex, complete or partially. These studies suggest that even the partial ablation of HLA expression can reduce the transplantation prerequisites and increase the chance

\section{Springer Open}

(c) The Author(s). 2021 Open Access This article is licensed under a Creative Commons Attribution 4.0 International License, which permits use, sharing, adaptation, distribution and reproduction in any medium or format, as long as you give appropriate credit to the original author(s) and the source, provide a link to the Creative Commons licence, and indicate if changes were made. The images or other third party material in this article are included in the article's Creative Commons licence, unless indicated otherwise in a credit line to the material. If material is not included in the article's Creative Commons licence and your intended use is not permitted by statutory regulation or exceeds the permitted use, you will need to obtain permission directly from the copyright holder. To view a copy of this licence, visit http://creativecommons.org/licenses/by/4.0/. 
of finding suitable donors for a certain patient. Until now, multiple attempts were made to eliminate the expression of HLA complex through targeting beta-2 microglobulin (B2M), by employing various approaches such as small interfering RNA (siRNA) [4-6] and zincfinger nuclease (ZFN) [7, 8].

CRISPR/Cas9 is an emerging strategy for genome editing and an efficient and promising technique revolutionizing this field [9-11]. A double-strand break (DSB) can be made easily by Cas 9 nuclease protein with the presence of a 20-nucleotide single guide RNA (gRNA), which recognizes a specific DNA region in the genome. Nonhomologous end joining (NHEJ) repair system can lead to a random insertion-deletion following DSB, while these mutations may eliminate the expression of the coding region of the target gene. In this study, we implemented CRISPR/Cas9 system to introduce DSB in the $H L A-A$ gene as a part of HLA class I to reduce minimum requirements for donor-recipient matching. We used double gRNA as a satisfactory approach to induce a large deletion and guarantee the disruption of the intended gene. The results from real-time PCR revealed a significant decrease in the expression of HLA-A genes, suggesting a targeted gene knockout in HEK293T cells.

\section{Methods}

\section{Construction and cloning of gRNAs}

The online CRISPR tool available at http://crispor.tefor. net/ [12] was used to design three gRNAs to target $H L A-A$. Since the HEK293T cell line is homozygous for HLA-A2, a combination of A-gRNA1 and A-gRNA3 was employed to expel an estimated 459 bp fragment between exons 2 and 3. In addition, A-gRNA2 was solitarily designed for a single guide approach, which in association with A-gRNA1 will be able to knockout $H L A-A$ gene regardless of allele type (Table 1). These oligonucleotides were inserted into PX458 (addgene, plasmid \#48148) expression plasmid to create PX458-AgRNA1 and PX458-A-gRNA3.

\section{Cell culture and transfection of HEK293T cell lines}

HEK293T cell line was cultured in Dulbecco's modified Eagle's medium supplemented with $10 \%$ fetal bovine serum and $500 \mu \mathrm{l}$ penicillin-streptomycin (Gibco, USA). Twenty-four hours prior to transfection, $5 \times 10^{5}$ cells were seeded in 6-well plates in a 2-ml cell growth medium without antibiotics. Equal concentration of

Table 1 gRNA sequences

\begin{tabular}{ll}
\hline Name of gRNA & gRNA sequence \\
\hline A-gRNA1 & ACAGCGACGCCGCGAGCCAG \\
A-gRNA2 & TACCGGCAGGACGCCTACGA \\
A-gRNA3 & TGCCGTCGTAGGCGTACTGG \\
\hline
\end{tabular}

PX458-A-gRNA1 and PX458-A-gRNA3 were cotransfected to HEK293T using lipofectamine 2000 (Invitrogen, USA).

\section{Isolation of transfected cells by FACS and establishment of single-cell clones}

Forty-eight hours post-transfection, the $\mathrm{GFP}^{+}$cells were sorted using fluorescence-activated cell sorting (FACS). Afterwards, the cells were cultured in complete growth media for 3-4 days and allowed to reach $70-80 \%$ confluency. Then, single cells were obtained from the heterogeneous population of transfected cells by performing serial dilution. Briefly, the cell suspension was prepared in a concentration of $10^{6}$ cells per $\mathrm{ml}$ of complete growth media, and the serial dilution was carried out to reach the concentration of 100 cells $/ \mathrm{ml}$. The concentration of a single cell per $100 \mu \mathrm{l}$ was obtained by adding 9-ml growth media to the cell suspension. Finally, $100 \mu \mathrm{l}$ of cell suspension was divided into each well of the 96-well plate to establish single cell clones (Fig. 1).

DNA extraction, PCR, and sequencing to analyze editing After expanding clones in 96-well plates, genomic DNA of each clone was extracted using a DNA extraction kit (Qiagen, Germany) according to the manufacturer's instruction. The following primers were used to amplify the intended target of genomic DNA extraction: forward: 5'-GCCCTGACCCAGACCTGG-'3 and reverse: 5'ATTGAGTGTGAAGCAGAGAACAAGG-'3. PCR was carried out using 30 cycles of heating at $95{ }^{\circ} \mathrm{C}$ for $30 \mathrm{~s}$, $65.5{ }^{\circ} \mathrm{C}$ for $25 \mathrm{~s}$, and $72^{\circ} \mathrm{C}$ for $50 \mathrm{~s}$, and PCR products were evaluated by gel electrophoresis. Next, PCR products were purified and integrated into the TA vector using the TOPO-TA cloning kit (Thermo Fisher Scientific, USA), and were further analyzed by Sanger sequencing.

\section{Real-time PCR}

To evaluate the impact of gene knockout on $H L A-A$ gene expression, real-time PCR was carried out in treated target cells. HEK293T cells were harvested by trypsin, and RNA was extracted using RNeasy Mini Kit (Qiagen, Germany) according to the manufacturer's protocol. Complementary DNA (cDNA) was synthesized, using Prime-Script 1st strand cDNA Synthesis Kit (Takara, Japan), according to the manufacturer's instructions. Real-time PCR was performed on QuantStudio 3 Real-Time PCR System (Applied Biosystem, USA), using high-ROX RealQ Plus 2x Master Mix Green (Ampliqon, Denmark) and specific primers for $H L A-A$ and Beta- 2microglobulin (B2M) genes (forward: 5'-ACCGTC CAGAGGATGTATG-'3, reverse: 5-'CTTTCAGGGCGATGTAATC-'3). The experiments were performed 


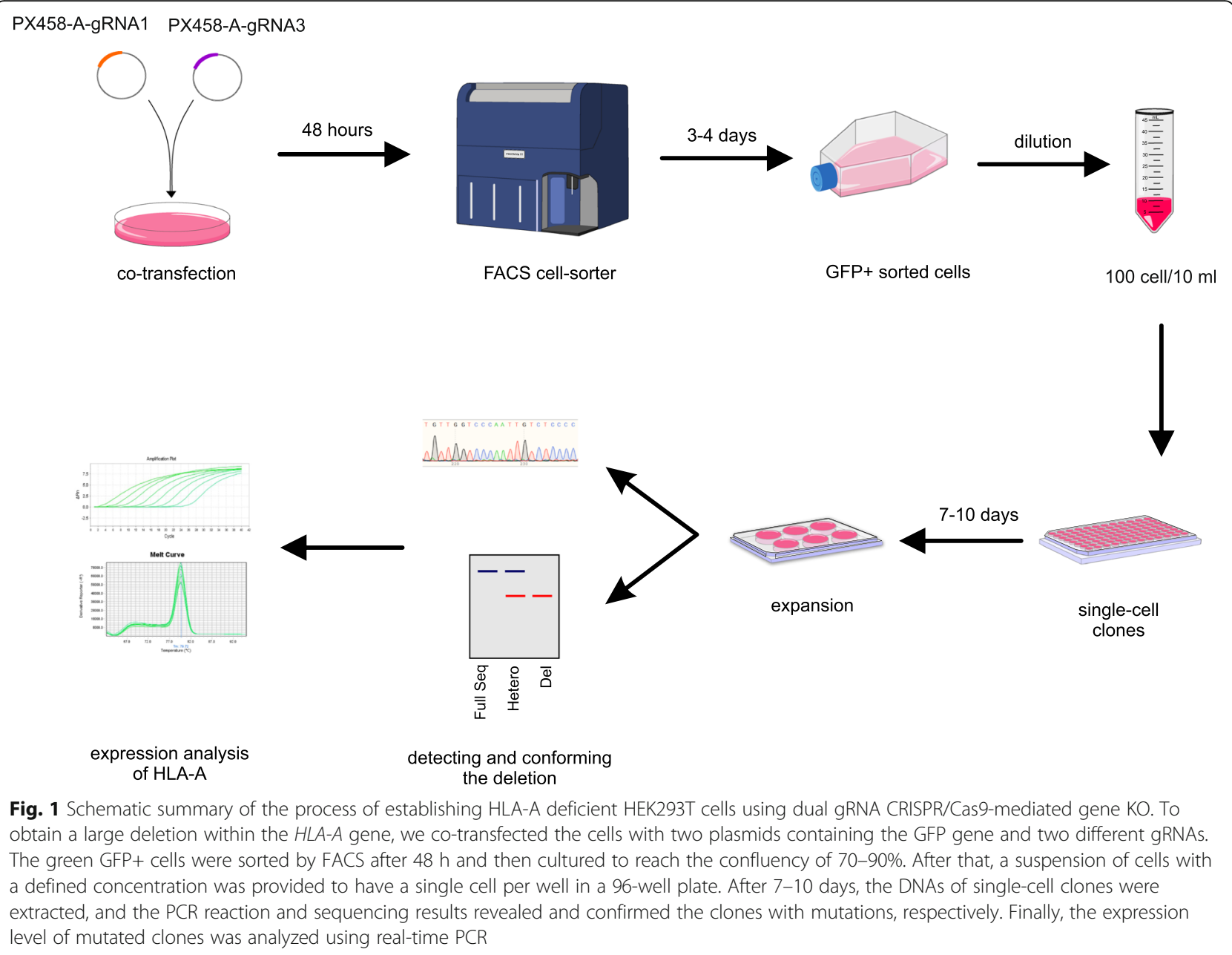

independently in a duplicate manner, and the relative expression of genes was analyzed using the $2-\Delta \Delta \mathrm{ct}$ method [13].

\section{Results}

Designing a universal gRNAs for HLA-A alleles

Since HLA genes are among the most polymorphic region of human genome, finding a consensus region among various alleles of an HLA gene was extremely difficult. We collected all $H L A-A$ allele sequences of ethnic groups, which cover $>99.9 \%$ of the Iranian population according to the Royan Public Umbilical Cord Blood Bank registry [14]. The coding sequences which were elicited from IPD-IMGT/HLA [15] were aligned simultaneously, and the appropriated gRNAs were picked out among the consensus regions. The criteria for designing the optimal gRNA were considered, and the most efficient gRNAs with the lowest off-target were selected (supplementary table). Initially, A-gRNA1 was picked as a universal gRNA. AgRNA1 could target most of the HLA-A alleles, except
HLA-A*01, which includes a significant portion (11.1\%) of the Iranian allelic population. Consequently, we committed to designing A-gRNA2, which has less allelic coverage (42.3\%) compared to A-gRNA1 (88.9\%), but it can cover HLA-A*01 (Fig. 2). Thus, A-gRNA1 and A-gRNA2 could be suggested to be used for ablation of HLA-A gene universally, regardless of the type of the allele.

\section{Transfection of vectors into the HEK293T cell line}

HEK293T cell line was selected as a model for the intended manipulations due to its high transfection efficiency, simple culturing, and a homologous allele for HLA-A (A*02:01). The cells were simultaneously transfected with two plasmids (PX458-A-gRNA1 and PX458A-gRNA3), and after that, a remarkable GFP signal was observed in transfected cells after $48 \mathrm{~h}$. Consequently, the $\mathrm{GFP}^{+}$cells were isolated from the transfected cell pool using FACSAria III $^{\mathrm{m}}$ (BD Biosciences, US) cell sorter (Fig. 3). 


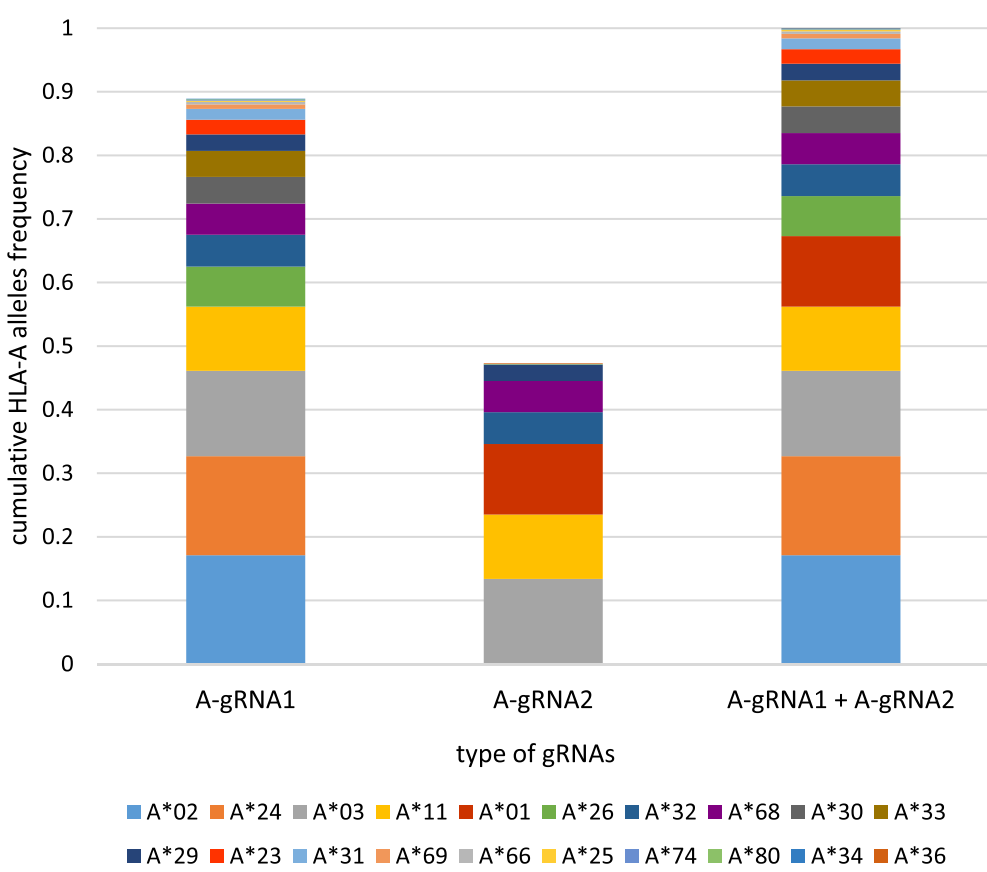

Fig. 2 Coverage of gRNAs for HLA-A alleles based on the frequencies in the Iranian population. Each column represents the possibility of each gRNA binding to its complementarity among HLA-A alleles. Each gRNA cannot be implemented for all ethnicities, so the last bar shows that all HLA-A alleles seem to be covered when both gRNAs are included

\section{Serial dilution and single-cell isolation}

Following the separation of GFP+ HEK293T cells, three types of cells were expected based on their HLA-A allele status: first, the cells without any alteration in the sequence of HLA-A gene; second, heterozygous cells with a deletion in single HLA-A allele; third, the homozygous cells in which both alleles completely abolished (Fig. 1). In order to isolate and detect homozygous and heterozygous cells, serial dilution was carried out to isolate single cells per well in 96-well plates. As a result, 22 wells out of 192 wells demonstrated to generate single-cell clones. The single-cell clones were further expanded for subsequent mutation analysis.

\section{Analysis of HLA-A null HEK293T cell lines by PCR and sequencing}

The PCR reaction was carried out on the genomic DNA of all of the expanded clones to determine the HLA-A allele status in each clone. PCR products on $2 \%$ agarose gel illustrated clones with a deletion in one HLA-A allele (heterozygous), deletion in both HLA-A alleles (homozygous), or without any mutation (wild-type). As demonstrated in Fig. 4, two clones (9.09\%) showed homozygous deletion in $H L A-A$, and 11 clones (50\%) showed heterozygous deletion in $H L A-A$. Moreover, analysis of the PCR products by Sanger sequencing further validated the deletions in genetically homogeneous clones.
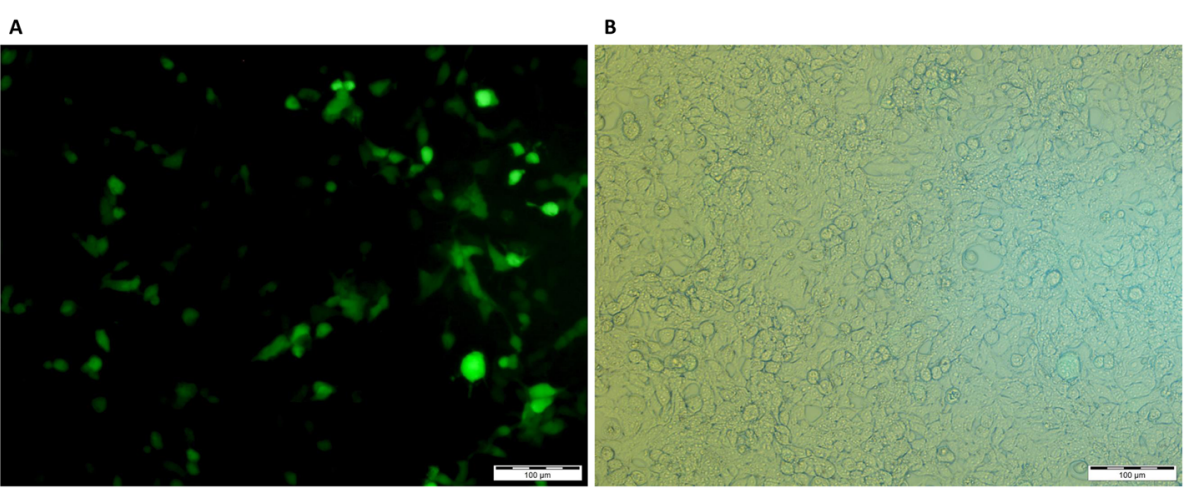

Fig. 3 Efficient transfection of pX458 plasmids into pX458 cells. a represents the GFP ${ }^{+}$cells visualized using fluorescent microscopy, and $\mathbf{b}$ shows the same cells with normal visible light (scale bars $100 \mu \mathrm{m}$ ) 
A

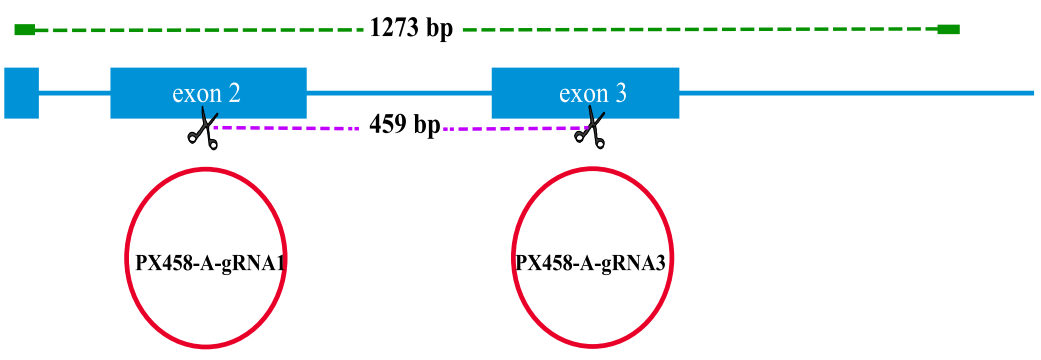

B
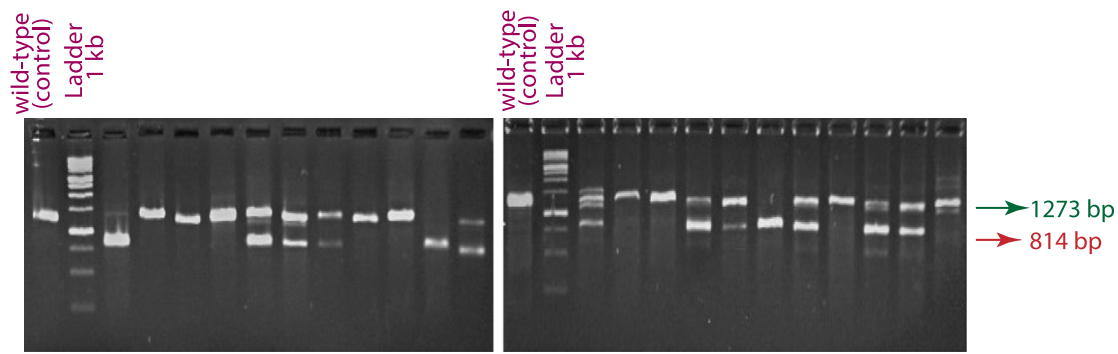

Fig. 4 a Schematic illustration of cleavage positions between exons 2 and 3 (459 bp) and primers locations for detecting desired deletion in HLAA gene. $\mathbf{b}$ Agarose gel electrophoresis of DNA extracted from single-cell colonies are showing colonies with deleted allele ( 814 bp) and wild-type allele (1273 bp)

Sequencing results revealed dual-Cas9-mediated doublestrand break (DSB) precisely in both alleles. Notably, both homozygote clones demonstrated cleavage three nucleotides upstream of PAM (Fig. 5).

\section{Expression of HLA-A in HEK293T}

Real-time PCR was performed to identify the expression levels of HLA-A in the HEK293T cell line. The results demonstrated that the levels of HLA-A mRNA expression in the two homozygous KO clones, namely F6 and C2, were diminished almost completely (Fig. 6).

\section{Discussion}

The minimum requirement for a successful engraftment between donor and recipient in HSCT is based on HLA-
A/-B/-C/-DRB1 matching, nominated as 8/8 HLAmatching. However, regarding the high allelic diversity for each locus, it is blatantly obvious that the probability of finding a potentially fully matched allogeneic donor is grossly small. In the absence of a fully matched donor, the alternative way is to refer to the unrelated donor through a local or global donor registry or receive transplantation from a donor with only a single mismatch for these loci (7/8 HLA match). However, it is associated with higher mortality and 1-year survival compared with 8/8 matched pairs [16]. Furthermore, umbilical cord blood is not a reliable source for HSCT due to the need for having sufficient recoverable cells besides matching of HLA-A, HLA-B (low resolution), and HLA-DRB1 (high resolution) [17-19]. Typically, the best situation

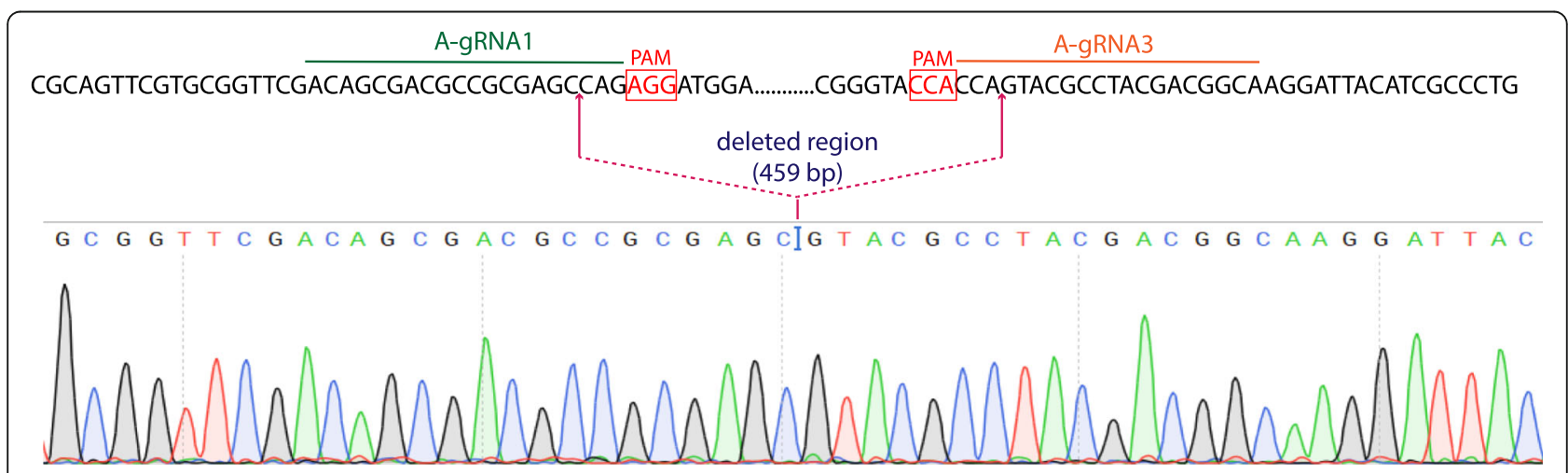

Fig. 5 Exact position of deleted sequence. Sanger sequencing results reveal 459 bp deleted region from the entire HLA-A gene 


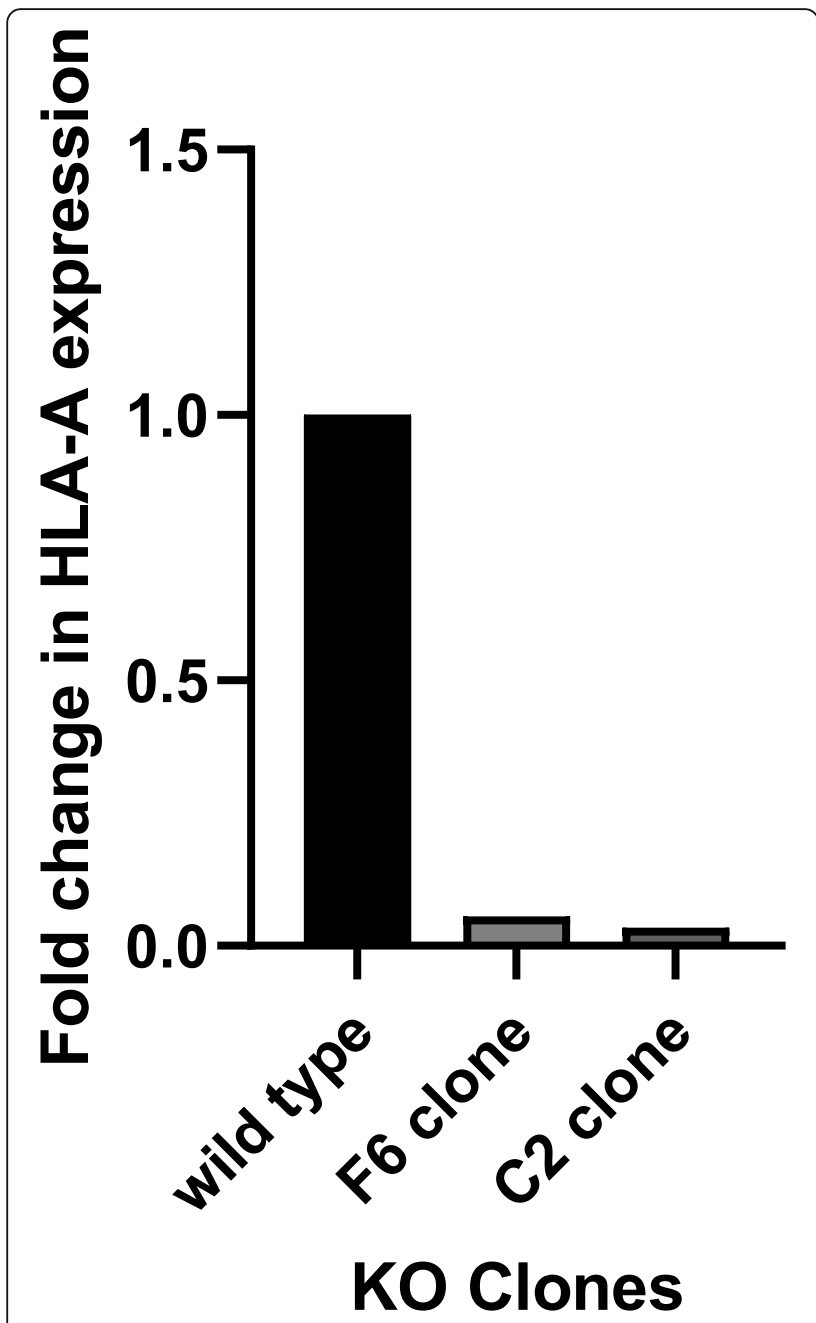

Fig. 6 The expression of HLA-A gene in both F6 and C2 clones was reduced significantly after HEK293T cells were transfected with PX458-A-gRNA1- and PX458-A-gRNA3-targeting CRISPR/Cas9 system

for finding a suitable donor is fully matched siblings. Unfortunately, the chance of finding a matched sibling is 15 to $30 \%$, depending on the number of children in a family [20-23]. Due to a lack of HLA registries and cord blood banks in many countries, consanguineous marriages provide the only available resource for a suitable donor $[24,25]$. In recent years, scientists have been looking for a way through genetic manipulation to address donor insufficiency and the following problems of allogeneic transplantation. With the emergence of RNAi, many researchers sought to knockdown the HLA class I [4-6, 26-28]; however, the significant challenge of RNAi technology is the transient silencing of the target gene. Although the problem of temporary expression was resolved with the advent of ZFN and transcription activator-like effector nuclease (TALEN) technologies, laborious engineering and cloning a novel protein is required to target the desired region on a gene, which restrains these technologies from being put to use for high-throughput applications.

Thus, eliminating one of the HLA gene families, regarding maintaining immunological manner, may facilitate finding a suitable donor. $H L A-A$ and $H L A-B$ were our candidates, which are more reliable to be knockout. However, designing a unique gRNA for $H L A-B$ is almost impossible because of massive allelic diversity in populations $[14,29]$. The main reason for not choosing HLA-C as a target gene was its inhibitory effects on NK cell receptors [30]. HLA-DRB1 was not chosen due to the linkage disequilibrium with $H L A-D Q B 1$; therefore, they may appear as a haplotype [31, 32].

Torikai et al. generated HLA-A deficient on engineered CD19 CAR T cells [7] and hematopoietic stem cells [8] using ZFN technology. They successfully demonstrated that eliminating the expression of HLA-A can maintain the hematopoiesis ability as well as increasing the probability of identifying a fitting donor; however, the complexity of designing a specific nuclease for the intended target remained a prominent challenge. Recently, different approaches have been implemented using CRISPR/Cas9 as an efficient and easier way of improving transplantation rather than previous technologies. For instance, thorough knockout of HLA class II $\beta$ chain genes was accomplished using a single guide toward producing HLA-II-compatible HSCs for transplantation [33]. HLA class I (B2M gene) and II (CIITA gene) were targeted in human-induced pluripotent stem cells (iPSCs) and differentiated into cardiomyocytes for generating universal donor of allogeneic transplantation [34]. Another engineered iPSC was successfully developed by abolishing HLA-A and HLA-B to overcome immune rejection induced by HLA disparity [35].

We hired CRISPR/Cas9 system to generate HLA-A null cells. With considering the frequency of Iranian HLA alleles [14], we applied dual gRNAs (A-gRNA1 and A-gRNA3) among few conserved sequences to make a large deletion (Fig. 3) as a straightforward and costbenefit method rather than single gRNA/Cas9 [36]. Although the efficiency for co-transfection of two vectors is less compared to the single-guide approach, introducing a large deletion could guarantee the ablation of the target gene. The possibility of A-gRNA1 for targeting $88.9 \%$ of allelic diversity in the Iranian population will make it to be used widely in future clinical trials; nevertheless, we designed another gRNA (A-gRNA2) to cover other alleles where A-gRNA1 cannot cover (Fig. 2). Even though we did not use A-gRNA2, it can be suggested for further studies. In this study, two clones (F6 and C2) received a large deletion in both alleles, and the sequencing results revealed the precise cleavage of Cas9 nuclease (Fig. 5). The real-time PCR further indicated that the expression of the $H L A-A$ gene was suppressed 
following gene disruption (Fig. 6). Albeit the efficiency of homozygous deletion was almost similar to Hong et al. [37], the efficiency of heterozygous deletion was higher $50 \%$ in comparison with $7.5 \%$ in Hong et al.'s study), regarding that they analyzed a wider range of single cells.

\section{Conclusion}

We demonstrated that the dual-gRNA approach in CRIS PR/Cas9 could lead to the elimination of the HLA-A gene. Despite the fact that the HLA gene family is highly polymorphic, we established universal gRNAs, which potentially can be used in clinical settings to knockout the $H L A-A$ gene. While HLA allele varieties are distributed with different frequencies around the world, our proposed universal gRNAs can be used in diverse ethnicities. Therefore, $H L A-A$ gene elimination can diminish transplantation requirement from $8 / 8$ allele match to the $6 / 6$ or $5 / 6$ considering one allele disparity between donor and recipient; as a result, finding a fully matched donor will be much more accessible. Further studies need to be conducted to demonstrate the applicability of gRNAs in human-derived hematopoietic stem cells with subsequent functional and immune assays.

\begin{abstract}
Abbreviations
B2M: Beta-2 microglobulin; Cas9: CRISPR-associated protein 9 nuclease; CRIS PR: Clustered regularly interspaced short palindromic repeats; DNA: Deoxyribonucleic acid; DSB: Double-strand break; FACS: Fluorescenceactivated cell sorting; GFP: Green fluorescent protein; gRNA: Single-guide RNA; GVHD: Graft-versus-host disease; HEK293T: Human embryonic kidney; HLA: Human leukocyte antigen; HSCT: Hematopoietic stem cell transplantation; iPSC: Induced pluripotent stem cells; KO: Knockout; NHEJ: Non-homologous end joining; NK cell: Natural killer cell; PCR: Polymerase chain reaction; RNA: Ribonucleic acid; siRNA: Small interfering RNA; TALEN: Transcription activator-like effector nucleases; ZFN: Zinc-finger nuclease
\end{abstract}

\section{Supplementary Information}

The online version contains supplementary material available at https://doi. org/10.1186/s43042-021-00155-y.

Additional file 1. Supplementary table

\section{Acknowledgements}

We would like to thank Dr. Shirin Farjadian for her precious help in immunological concepts of the study. We are also grateful to Dr. Mohsen Mazloomrezaei, all members of Department of Medical Genetics, and Central Laboratory of Shiraz University of Medical Sciences for technical assistance on this work.

\section{Authors' contributions}

FA carried out all of the experiment with the support from MR. FA and MP wrote the manuscript. MN contributed in carrying out and the interpretation of RT-PCR. MD designed and supervised the study. All authors have read and approved the manuscript.

\section{Funding}

This manuscript was extracted from the MSc thesis of Farshid Amiri and was supported by a grant (95-01-01-13882) from the Vice-Chancellor for Research Affairs of Shiraz University of Medical Sciences, Shiraz, Iran.

\section{Availability of data and materials}

The datasets used and/or analyzed during the current study are available from the corresponding author on reasonable request.

\section{Declarations}

Ethics approval and consent to participate

Not applicable

\section{Consent for publication}

Not applicable

\section{Competing interests}

The authors declare that they have no competing interests.

\section{Author details}

'Department of Medical Genetics, School of Medicine, Shiraz University of Medical Sciences, Shiraz, Iran. ${ }^{2}$ Diagnostic Laboratory Sciences and Technology Research Center, Paramedical School, Shiraz University of Medical Sciences, Shiraz, Iran. ${ }^{3}$ Stem Cell Technology Research Center, Shiraz University of Medical Sciences, Shiraz, Iran.

Received: 19 October 2020 Accepted: 5 March 2021

Published online: 05 May 2021

\section{References}

1. Park B, Yoo KH, Kim C (2015) Hematopoietic stem cell expansion and generation: the ways to make a breakthrough. Blood Res Kor Soc Hematol 50:194-203

2. Ciurea SO, Thall PF, Wang X, Wang SA, Hu Y, Cano P et al (2011) Donorspecific anti-HLAAbs and graft failure in matched unrelated donor hematopoietic stem cell transplantation. Blood. 118(22):5957-5964. https:// doi.org/10.1182/blood-2011-06-362111

3. Bray RA, Hurley CK, Kamani NR, Woolfrey A, Müller C, Spellman S et al (2008) National Marrow Donor Program HLA matching guidelines for unrelated adult donor hematopoietic cell transplants. Biol Blood Marrow Transplant 14(9 SUPPL):45-53. https://doi.org/10.1016/j.bbmt.2008.06.014

4. Figueiredo C, Seltsam A, Blasczyk R (2006) Class-, gene-, and group-specific HLA silencing by lentiviral shRNA delivery. J Mol Med 84(5):425-437. https:// doi.org/10.1007/s00109-005-0024-2

5. Gonzalez S, Castanotto D, Li H, Olivares S, Jensen MC, Forman SJ, Rossi JJ, Cooper LN (2005) Amplification of RNA-targeting HLA mRNAs. Mol Ther 11(5):811-818. https://doi.org/10.1016/j.ymthe.2004.12.023

6. Deuse T, Seifert M, Phillips N, Fire A, Tyan D, Kay M, et al (2011) Human leukocyte antigen I knockdown human embryonic stem cells induce host ignorance and achieve prolonged xenogeneic survival. Circulation 124(11 SUPPL. 1)

7. Torikai H, Reik A, Soldner F, Warren EH, Yuen C, Zhou Y, Crossland DL, Huls H, Littman N, Zhang Z, Tykodi SS, Kebriaei P, Lee DA, Miller JC, Rebar EJ, Holmes MC, Jaenisch R, Champlin RE, Gregory PD, Cooper LJN (2013) Toward eliminating HLA class I expression to generate universal cells from allogeneic donors. Blood. 122(8):1341-1349. https://doi.org/10.1182/blood-2 013-03-478255

8. Torikai H, Mi T, Gragert L, Maiers M, Najjar A, Ang S et al (2016) Genetic editing of HLA expression in hematopoietic stem cells to broaden their human application. Sci Rep 6(1):21757 Available from: http://www.nature. com/articles/srep21757

9. Doudna JA, Charpentier E (2014) The new frontier of genome engineering with CRISPR-Cas9. Science (80- ) 346(6213):1258096-1258096 [cited 2018 Jul 5]. Available from: http://www.ncbi.nlm.nih.gov/pubmed/25430774

10. Wang H, La Russa M, Qi LS (2016) CRISPR/Cas9 in genome editing and beyond. Annu Rev Biochem 85(1):227-264 Available from: http://www.a nnualreviews.org/doi/10.1146/annurev-biochem-060815-014607

11. Pirouzfar M, Amiri F, Dianatpour M, Takhshid MA (2020) CRISPR/Cas9mediated knockout of mll5 enhances apoptotic effect of cisplatin in hela cells in vitro. EXCLI J 19:170-182

12. Haeussler M, Schönig K, Eckert $H$, Eschstruth A, Mianné J, Renaud J-B et al (2016) Evaluation of off-target and on-target scoring algorithms and integration into the guide RNA selection tool CRISPOR. Genome Biol 17(1): 148 [cited 2019 Dec 19]. Available from: http://genomebiology. biomedcentral.com/articles/10.1186/s13059-016-1012-2 
13. Livak KJ, Schmittgen TD (2001) Analysis of relative gene expression data using real-time quantitative PCR and the $2-\Delta \Delta C T$ method. Methods. 25(4): 402-408. https://doi.org/10.1006/meth.2001.1262

14. Ebrahimkhani S, Farjadian S, Ebrahimi M (2014) The Royan public umbilical cord blood Bank: does it cover all ethnic groups in Iran based on HLA diversity. Transfus Med Hemother 41(2):134-138

15. Robinson J, Halliwell JA, Hayhurst JD, Flicek P, Parham P, Marsh SGE (2015) The IPD and IMGT/HLA database: allele variant databases. Nucleic Acids Res 43(D1):D423-D431 [cited 2019 Dec 16]. Available from: http://academic.oup. com/nar/article/43/D1/D423/2438496/The-IPD-and-IMGTHLA-database-a llele-variant

16. Lee SJ, Klein J, Haagenson M, Baxter-Lowe LA, Confer DL, Eapen M et al (2007) High-resolution donor-recipient HLA matching contributes to the success of unrelated donor marrow transplantation. Blood 110(13):45764583 [cited 2018 Jul 25]. Available from: http://www.ncbi.nlm.nih.gov/ pubmed/17785583

17. Barker JN, Scaradavou A, Stevens CE (2010) Combined effect of total nucleated cell dose and HLA match on transplantation outcome in 1061 cord blood recipients with hematologic malignancies. Blood. 115(9):18431849. https://doi.org/10.1182/blood-2009-07-231068

18. Ballen KK, Gluckman E, Broxmeyer HE (2013) Umbilical cord blood transplantation: the first 25 years and beyond. Blood 122:491-498

19. Rocha V (2016) Umbilical cord blood cells from unrelated donor as an alternative source of hematopoietic stem cells for transplantation in children and adults. Semin Hematol 53(4):237-245. https://doi.org/10.1053/j. seminhematol.2016.08.002

20. Souillet G, Rey S, Bertrand Y, Pujol M, Pondarré C, Bourgeot JP et al (2000) Outcome of unrelated bone marrow donor searches in 174 children resulting in 45 patients transplanted in the HLA-matched and -mismatched situation. Bone Marrow Transplant 26(1):31-43 [cited 2018 Aug 1]. Available from: http://www.nature.com/articles/1702460

21. Kumar P, Defor TE, Brunstein C, Barker JN, Wagner JE, Weisdorf DJ et al (2008) Allogeneic hematopoietic stem cell transplantation in adult acute lymphocytic leukemia: impact of donor source on survival. Biol Blood Marrow Transplant 14(12):1394-1400 [cited 2018 Aug 1]. Available from: http://linkinghub.elsevier.com/retrieve/pii/S1083879108004205

22. Camitta B, Ash R, Menitove J, Murray K, Lawton C, Hunter J et al (1989) Bone marrow transplantation for children with severe aplastic anemia: use of donors other than HLA-identical siblings. Blood 74(5):1852-1857 [cited 2018 Aug 1]. Available from: http://www.ncbi.nlm.nih.gov/pubmed/2529004

23. Petersdorf EW (2008) Optimal HLA matching in hematopoietic cell transplantation. Curr Opin Immunol 20(5):588-593 [cited 2018 Aug 1]. Available from: http://www.ncbi.nlm.nih.gov/pubmed/18674615

24. Louw VJ, Heyns ADP (2010) The role of the state in establishing a public cord blood stem cell bank. S Afr Med J 100(5):292-294 [cited 2018 Aug 1]. Available from: http://www.ncbi.nlm.nih.gov/pubmed/20460020

25. Hamidieh AA, Ostadali Dehaghi M, Paragomi P, Navaei S, Jalali A, Ghazizadeh Eslami G et al (2015) Efficiency of allogeneic hematopoietic SCT from HLA fully-matched non-sibling relatives: a new prospect of exploiting extended family search. Bone Marrow Transplant 50(4):545-552Available from: https://doi.org/10.1038/bmt.2014.307

26. Haga K, Lemp NA, Logg CR, Nagashima J, Faure-Kumar E, Gomez GG, Kruse CA, Mendez R, Stripecke R, Kasahara N, Cicciarelli JC (2006) Permanent, lowered HLA class I expression using lentivirus vectors with shRNA constructs: averting cytotoxicity by alloreactive T lymphocytes. Transplant Proc 38(10):3184-3188. https://doi.org/10.1016/j.transproceed.2006.10.158

27. Figueiredo C, Goudeva L, Horn PA, Eiz-Vesper B, Blasczyk R, Seltsam A (2010) Generation of HLA-deficient platelets from hematopoietic progenitor cells. Transfusion. 50(8):1690-1701. https://doi.org/10.1111/j.1537-2995.2010.02644.x

28. Wiegmann B, Figueiredo C, Gras C, Pflaum M, Schmeckebier S, Korossis S, Haverich A, Blasczyk R (2014) Prevention of rejection of allogeneic endothelial cells in a biohybrid lung by silencing HLA-class I expression. Biomaterials. 35(28):8123-8133. https://doi.org/10.1016/j.biomaterials.2014.06. 007

29. González-Galarza FF, Takeshita LYC, Santos EJM, Kempson F, Maia MHT, da Silva ALS et al (2015) Allele frequency net 2015 update: new features for HLA epitopes, KIR and disease and HLA adverse drug reaction associations. Nucleic Acids Res 43(D1):D784-D788 [cited 2019 Jan 20]. Available from: http://academic.oup.com/nar/article/43/D1/D784/2438866/Allele-frequencynet-2015-update-new-features-for
30. Colonna M, Borsellino G et al HLA-C is the inhibitory ligand that determines dominant resistance to lysis by NK1-and NK2-specific natural killer cells. Nat Acad Sci [cited 2018 Aug 4]; Available from: http://www.pnas.org/content/ 90/24/12000.short

31. Nowak J (2008) Role of HLA in hematopoietic SCT. Bone Marrow Transplant 42(SUPPL. 2):71-76

32. Petersdorf EW (2013) Genetics of graft-versus-host disease: the major histocompatibility complex. Blood Rev 27(1):1-12 [cited 2018 Jul 25]. Available from: http://linkinghub.elsevier.com/retrieve/pii/S0268960X12 000720

33. Crivello P, Ahci M, Maaßen F, Wossidlo N, Arrieta-Bolaños E, Heinold A, Lange V, Falkenburg JHF, Horn PA, Fleischhauer K, Heinrichs S (2019) Multiple knockout of classical HLA class II $\beta$-chains by CRISPR/Cas9 genome editing driven by a single guide RNA. J Immunol 202(6):1895-1903. https:// doi.org/10.4049/jimmunol.1800257

34. Mattapally S, Pawlik KM, Fast VG, Zumaquero E, Lund FE, Randall TD et al (2018) Human leukocyte antigen class I and II knockout human induced pluripotent stem cell-derived cells: universal donor for cell therapy. J Am Heart Assoc 7(23):1-13

35. Xu H, Wang B, Ono M, Kagita A, Fujii K, Sasakawa N et al (2019) Targeted disruption of HLA genes via CRISPR-Cas9 generates iPSCs with enhanced immune compatibility. Cell Stem Cell 24(4):566-578.e7. https://doi.org/10.1 016/j.stem.2019.02.005

36. Pathak B, Zhao S, Manoharan M, Srivastava V (2019) Dual-targeting by CRIS PR/Cas9 leads to efficient point mutagenesis but only rare targeted deletions in the rice genome. 3 Biotech 9(4)

37. Hong C, Sohn H, Lee H, Cho H, Kim T (2017) Antigen presentation by individually transferred HLA class I generated using the multiplex CRISPRCas9 system. J Immunother 40(6):201-210. https://doi.org/10.1097/CJI. 0000000000000176

\section{Publisher's Note}

Springer Nature remains neutral with regard to jurisdictional claims in published maps and institutional affiliations.

\section{Submit your manuscript to a SpringerOpen ${ }^{\circ}$ journal and benefit from:}

- Convenient online submission

- Rigorous peer review

- Open access: articles freely available online

High visibility within the field

- Retaining the copyright to your article

Submit your next manuscript at $>$ springeropen.com 